\title{
Delayed Thrombectomy Center Arrival is Associated with Decreased Treatment Probability
}

\author{
Meah M. Gao (D), Jeffrey Z. Wang, Jane Liao, Stephanie D. Reiter, \\ Manav V. Vyas (D), Elizabeth Linkewich, Richard H. Swartz, \\ Leodante da Costa, Charles D. Kassardjian (D), Amy Y. X. Yu (D)
}

\begin{abstract}
Background: Endovascular thrombectomy (EVT) is effective in reducing disability in selected patients with stroke and large vessel occlusion (LVO), but access to this treatment is suboptimal. Aim: We examined the proportion of patients with LVO who did not receive EVT, the reasons for non-treatment, and the association between time from onset and probability of treatment. Methods: We conducted a retrospective cohort study of consecutive patients with acute stroke and LVO presenting between January 2017 and June 2018. We used multivariable log-binomial models to determine the association between time and probability of treatment with and without adjustment for age, sex, dementia, active cancer, baseline disability, stroke severity, and evidence of ischemia on computerized tomography. Results: We identified 256 patients (51\% female, median age 74 [interquartile range, IQR 63.5, 82.5]), of whom 59\% did not receive EVT. The main reasons for not treating with EVT were related to occlusion characteristics or infarct size. The median time from onset to EVT center arrival was longer among non-treated patients $(218$ minutes $[142,302])$ than those who were treated (180 minutes [104, 265], $\mathrm{p}=0.03$ ). Among patients presenting within 6 hours of onset, the relative risk (RR) of receiving EVT decreased by $3 \%$ with every 10-minute delay in arrival to EVT center (adjusted $\left.\mathrm{RR} 0.97 \mathrm{CI}_{95}[0.95,0.99]\right)$. This association was not found in the overall cohort. Conclusions: The proportion of patients with acute stroke and confirmed LVO who do not undergo EVT is substantial. Minimizing delays in arrival to EVT center may optimize the delivery of this treatment.
\end{abstract}

RÉSUMÉ : Le fait de se présenter de façon tardive à un centre désigné offrant la thrombectomie endovasculaire peut être associé à une diminution des possibilités d'un tel traitement. Contexte : La thrombectomie endovasculaire (TE) est efficace pour réduire l'invalidité de certains patients victimes d'un AVC et d'occlusion de leurs grosses artères. Cela dit, l'accès à une telle intervention demeure encore sous-optimal. Objectif : Nous nous sommes penchés sur la proportion de patients victimes d'occlusion de leurs grosses artères qui n'ont pas bénéficié de TE mais aussi sur les raisons de cette absence d'intervention et sur les liens entre le temps s'étant écoulé à partir des premiers signes d'un AVC et la probabilité de bénéficier de la TE. Méthodes : Pour ce faire, nous avons effectué une étude de cohorte rétrospective portant sur des patients vus consécutivement. Victimes d'un AVC aigu, donnant à voir une occlusion de leurs grosses artères, ces patients ont eu recours à des soins entre janvier 2017 et juin 2018. Nous avons utilisé des modèles logistiques-binomiaux multivariés afin de déterminer l'association entre le temps s'étant écoulé à partir des premiers signes d'un AVC et la probabilité d'obtenir un traitement de TE, et ce, avec ou sans ajustement en fonction de l'âge, du sexe, de la présence de démence, du fait de souffrir d'un cancer actif, du niveau d'invalidité à partir des premiers signes de l'AVC, de la gravité de l'AVC et de la présence d'ischémie détectée par tomodensitométrie. Résultats : Nous avons ainsi identifié 256 patients (51\% étant des femmes ; âge médian : 74 ans [EI 63,5 - 82,5]). De ce total, 59\% d'entre eux n'ont pas bénéficié d'un traitement de TE. Les principaux motifs pour ne pas recourir à cette intervention étaient liés aux caractéristiques mêmes des occlusions et à la taille des infarctus. Le délai médian entre les premiers signes de l'AVC et l'arrivée des patients à un centre désigné offrant la TE s'est révélé plus long chez les patients en fin de compte non-traités (218 minutes [142,302]) que chez ceux qui ont eu accès à un traitement de TE (180 minutes [104,265], $p=$ 0,03). Parmi les patients s'étant présentés dans les 6 heures suivant les premiers signes d'un AVC, le risque relatif (RR) de bénéficier d'une TE a diminué de $3 \%$ pour chaque délai additionnel de 10 minutes d'arrivée des patients (RR ajusté 0,97 ; IC $95 \%$ [0,95 - 0,99]). Il est à noter qu'une telle association n'a pas été observée dans l'ensemble de la cohorte. Conclusions : En conséquence, la proportion de patients victimes d'un AVC aigu et souffrant d'occlusion de leurs grosses artères qui ne bénéficie pas d'un traitement de TE apparaît considérable. En réduisant les délais d'arrivée à un centre désigné offrant la TE, il se pourrait donc qu'on soit en mesure d'optimiser l'administration de ce traitement.

Keywords: Stroke, Endovascular, Health services research doi:10.1017/cjn.2020.95

Can J Neurol Sci. 2020; 47: 770-774

From the Department of Medicine (Neurology), University of Toronto, Toronto, Ontario, Canada (MMG, JZW, JL, SDR, MVV, RHS, CDK, AYXY); Sunnybrook Health Sciences Center, Toronto, Ontario, Canada (MVV, EL, RHS, LC, AYXY); Institute of Health Policy, Management and Evaluation, Toronto, Ontario, Canada (MVV); Department of Surgery, University of Toronto, Toronto, Ontario, Canada (LC); St. Michael's Hospital, Toronto, Ontario, Canada (CDK); and Department of Occupational Science and Occupational Therapy, University of Toronto, Toronto, Ontario, Canada (EL)

Received December 11, 2019. Final Revisions Submitted April 27, 2020. Date of Acceptance May 9, 2020.

Correspondence to: Meah M. Gao, Department of Medicine (Neurology), University of Toronto, 5W-West Toronto Western Hospital, Toronto, Canada. Email: meah.gao@mail.utoronto.ca 


\section{INTRODUCTION}

Endovascular thrombectomy (EVT) improves outcomes in patients with acute ischemic stroke and large vessel occlusion (LVO). ${ }^{1-3}$ Acute stroke guidelines recommend consideration for EVT treatment up to 24 hours after last seen normal time in selected patients with LVO. ${ }^{4}$ However, not all patients with LVO assessed at an EVT center ultimately receive this treatment and little is known about the number and clinical characteristics of patients with LVO who do not undergo EVT. ${ }^{5}$ Furthermore, while increasing time from stroke onset to revascularization is associated with poorer outcomes, ${ }^{6,7}$ the association between time from last seen normal to assessment at an EVT center and the likelihood of receiving treatment is not well understood.

\section{AIMS AND/Or HYPOTHESIS}

We aimed to describe the proportion and characteristics of patients with acute ischemic stroke and confirmed LVO who do not undergo EVT after assessment at a comprehensive stroke center, as well as the rationale for non-treatment. We examined the association between time from last seen normal to arrival at an EVT center and the risk of non-treatment. We hypothesized that longer time delays may be associated with lower probability of receiving EVT.

\section{Methods}

\section{Study Design and Data Collection}

We conducted a retrospective cohort study of patients with acute ischemic stroke who presented between January 1, 2017 and June 30, 2018 to our institution, a university-affiliated comprehensive stroke center that provides consultation for EVT to a catchment area of 2.5 million people with six referring sites, approximately 800 acute stroke admissions, and 110 EVT cases annually. We included all patients who presented with acute ischemic stroke within 24 hours of last seen normal time with LVO either directly to our emergency department or after interhospital transfer from a non-EVT center. We did not include patients who experienced in-hospital stroke.

We defined LVO as (1) occlusions of the terminal internal carotid artery, M1 segment of the middle cerebral artery, or basilar artery ${ }^{8}$ and (2) occlusions of M2 segment of middle cerebral artery, proximal anterior cerebral artery, proximal posterior cerebral artery, or distal vertebral artery with documentation of interventional neuroradiology consultation for EVT consideration. We used this more inclusive definition of LVO in order to reflect the real-world practice that EVT may be pursued in selected patients with clinically significant deficits and occlusion in a branch of the middle cerebral, basilar, or posterior cerebral arteries. $^{9-11}$

Patient characteristics, medical comorbidities, time metrics, stroke severity, neuroimaging findings, hyperacute treatments (intravenous thrombolysis and/or EVT), and reasons for nontreatment were obtained by retrospective chart review. This study was approved by our institutional Research Ethics Board with a waiver of individual patient consent.

\section{Statistical Methods}

Baseline characteristics were compared using the KruskalWallis test for continuous variables and the $\chi^{2}$ test for categorical variables. We calculated unadjusted and adjusted relative risk (RR) and 95\% confidence intervals (CI) of receiving EVT using multivariable log-binomial models with time as a continuous variable measured in 10-minute intervals and displayed the probability of receiving EVT from the fitted model. We performed a subgroup analysis in patients arriving to EVT center within 6 hours of last seen normal versus beyond. Covariates were selected a priori based on clinical relevance. The covariates in the multivariable model were age (continuous), sex, dementia, active cancer, baseline modified Rankin Scale (mRS) score, categorized into independent $(<2)$ versus non-independent $(\geq 2)$, minor stroke (National Institutes of Health Stroke Scale $<5$ ), and favorable non-contrast computerized tomography (CT) scan performed at the EVT center, defined as reported Alberta Stroke Program Early CT Score (ASPECTS) $>5$ or lack of advanced ischemic changes. We also performed stratified unadjusted analyses by sex, occlusion site, and inter-hospital transfer. All analyses were performed using SAS 9.4 (SAS Institute Inc., Cary, NC, USA).

\section{Results \\ Baseline Characteristics}

Of 1032 acute stroke activations during the study period, 256 patients met study criteria. The median age was 74 (interquartile range [IQR] 64, 82) years, $51 \%$ were female, and $63 \%$ arrived after inter-hospital transfer from a non-EVT center. Most transferred patients had imaging confirmed LVO prior to transfer $(95 \%, 153 / 162)$ and the remaining nine patients were transferred based on clinical judgment. Most transferred patients, 91\% (148/ 162), underwent neurovascular imaging at the EVT center. Table 1 shows the patient baseline characteristics. Compared to the patients who underwent EVT, the 150 (59\%) patients who did not undergo EVT were older, less likely to be living at home or to be independent $(\mathrm{mRS}<2)$, and more likely to present with milder strokes or symptoms upon waking up, arrive after inter-hospital transfer, and experience a longer time to arrival to EVT center. Additionally, patients who received EVT treatment were also more likely to have favorable CT scan and proximal anterior circulation occlusion on repeat neuroimaging at the EVT center than those who did not undergo EVT. There was no statistically significant difference in prevalence of pre-existing medical comorbidities between the two groups. Furthermore, treatment with intravenous thrombolysis was similar between the EVT-treated and non-treated patients.

\section{Reasons for Non-Treatment and Transfer Status}

Among patients who arrived directly to the EVT center, 54\% of the patients underwent EVT. The most frequent reason for not pursuing EVT was because the lesion was non-suitable or inaccessible (18\%), including lesions the interventional neuroradiologist felt were sub-occlusive, too distal, or inaccessible due to poor vascular access. The second most common reason was extensive infarct (11\%), followed by mild stroke severity (10\%), as shown in Table 2. Among patients who arrived after an interhospital transfer, only 34\% received EVT. About 30\% patients ( $n=49$ ) with confirmed LVO prior to transfer had complete or partial recanalization of the occlusion or distal migration of the thrombus on repeat imaging after transfer. Of these patients, 41 received intravenous thrombolysis prior to transfer. Other reasons 
Table 1: Baseline characteristics by EVT treatment $(n=256)$

\begin{tabular}{|c|c|c|c|}
\hline Patient characteristics & EVT $n=106$ & No EVT $n=150$ & p-Value \\
\hline Median age (IQR) & $73(62,80)$ & $76(65,85)$ & 0.02 \\
\hline Female sex, n (\%) & $51(48.1)$ & $79(52.7)$ & 0.53 \\
\hline Baseline $\mathrm{mRS}<2, \mathrm{n}(\%)$ & $17(16.4)$ & $28(28.5)$ & 0.03 \\
\hline Baseline living at home, $\mathrm{n}(\%)$ & $101(97.1)$ & $134(90.5)$ & 0.04 \\
\hline \multicolumn{4}{|l|}{ Comorbidities, n (\%) } \\
\hline Prior cerebrovascular disease & $23(21.7)$ & $30(20.0)$ & 0.76 \\
\hline Hypertension & $58(54.7)$ & $90(60.0)$ & 0.44 \\
\hline Congestive heart failure & $11(10.3)$ & $17(11.3)$ & 0.84 \\
\hline Coronary artery disease & $26(24.3)$ & $27(18.0)$ & 0.27 \\
\hline Diabetes & $19(17.9)$ & $34(22.7)$ & 0.43 \\
\hline Dyslipidemia & $46(43.4)$ & $69(46.0)$ & 0.70 \\
\hline Atrial fibrillation & $24(22.6)$ & $37(24.7)$ & 0.77 \\
\hline Active smoking & $11(10.4)$ & $17(11.3)$ & 0.84 \\
\hline Peripheral artery disease & $1(0.9)$ & $2(1.3)$ & 1.00 \\
\hline Chronic kidney disease & $2(1.9)$ & $10(6.7)$ & 0.13 \\
\hline Active cancer & $3(2.8)$ & $7(4.7)$ & 0.53 \\
\hline Dementia & $7(6.6)$ & $14(9.3)$ & 0.50 \\
\hline $\begin{array}{l}\text { Symptoms upon awakening, } \\
\mathrm{n}(\%)\end{array}$ & $17(16)$ & $11(7.3)$ & 0.04 \\
\hline $\begin{array}{l}\text { Time from last seen normal to } \\
\text { EVT center arrival }<6 \text { hours, } \\
\mathrm{n}(\%)\end{array}$ & $87(82.1)$ & $122(81.3)$ & 1.00 \\
\hline Inter-hospital transfer, n (\%) & $55(51.9)$ & $107(71.3)$ & 0.002 \\
\hline $\begin{array}{l}\text { Median time to EVT center } \\
\text { (minutes, IQR) }\end{array}$ & $180(104-265)$ & $218(148-302)$ & 0.03 \\
\hline \multicolumn{4}{|l|}{ NIHSS at EVT center } \\
\hline Median NIHSS (IQR) & $19(12,22)$ & $13(4,22)$ & $<0.001$ \\
\hline NIHSS $<5, \mathrm{n}(\%)$ & $3(2.8)$ & $38(25.3)$ & $<0.001$ \\
\hline Favorable scan, n (\%) & $95(89.5)$ & $109(74.2)$ & 0.005 \\
\hline \multicolumn{3}{|l|}{ Location of occlusion } & \multirow[t]{2}{*}{0.002} \\
\hline $\begin{array}{l}\text { Proximal anterior circulation, } \\
\mathrm{n}(\%)\end{array}$ & $76(71.7)$ & $65(47.5)$ & \\
\hline $\begin{array}{l}\text { Distal anterior circulation, } \\
\mathrm{n}(\%)\end{array}$ & $20(18.7)$ & $58(42.3)$ & \\
\hline Posterior circulation, $\mathrm{n}(\%)$ & $10(9.4)$ & $14(10.2)$ & \\
\hline $\begin{array}{l}\text { Intravenous thrombolysis, } \\
\mathrm{n}(\%)\end{array}$ & $68(64.2)$ & $93(62.0)$ & 0.79 \\
\hline
\end{tabular}

$\mathrm{IQR}=$ interquartile range; $\mathrm{EVT}=$ endovascular thrombectomy; $\mathrm{mRS}=\mathrm{mo}-$ dified Rankin Scale, LSN=last seen normal; NIHSS=National Institute of Health Scale Score, Favorable scan: ASPECTS > 5 or lack of advanced ischemic changes, Proximal anterior circulation: terminal internal carotid artery, M1 of middle cerebral artery and proximal anterior cerebral artery, Distal anterior circulation: M2 of middle cerebral artery, Posterior circulation: distal vertebral artery, basilar artery, and proximal posterior cerebral artery.

for non-treatment after transfer include infarct progression $(25 \%)$ and mild stroke severity (9\%). In the non-treatment group, $74 \%$ had favorable scans at the EVT center. Among the 109 nontreated patients with favorable scans, the reasons for non-
Table 2: EVT treatment and reasons for non-treatment by transfer status $(n=256)$

\begin{tabular}{l|c|c|c}
\hline & $\begin{array}{c}\text { Direct } \\
\mathbf{n = 9 4}\end{array}$ & $\begin{array}{c}\text { Transfer } \\
\mathbf{n = 1 6 2}\end{array}$ & $\begin{array}{c}\text { Total } \\
\mathbf{n}=\mathbf{2 5 6}\end{array}$ \\
\hline Received EVT & $51(54 \%)$ & $55(34 \%)$ & $106(41 \%)$ \\
\hline Not received EVT & $43(46 \%)$ & $107(66 \%)$ & $150(59 \%)$ \\
\hline Infarct deemed too extensive & $10(11 \%)$ & $40(25 \%)$ & $50(20 \%)$ \\
\hline Mild stroke severity & $9(10 \%)$ & $14(9 \%)$ & $23(9 \%)$ \\
\hline Comorbidities preclude EVT & $6(6 \%)$ & $3(2 \%)$ & $9(4 \%)$ \\
\hline Patient did not consent to EVT & $1(1 \%)$ & $1(1 \%)$ & $2(1 \%)$ \\
\hline Causes related to occlusion characteristics & $17(18 \%)$ & $49(30 \%)$ & $66(26 \%)$ \\
\hline $\begin{array}{l}\text { Occlusion not suitable or inaccessible for } \\
\text { EVT }\end{array}$ & $17(18 \%)$ & NA & $17(7 \%)$ \\
\hline $\begin{array}{l}\text { Post-transfer partial recanalization or } \\
\text { thrombus migration }\end{array}$ & NA & $32(20 \%)$ & $32(12.5 \%)$ \\
\hline \begin{tabular}{l} 
Post-transfer vessel recanalization \\
\hline
\end{tabular}
\end{tabular}

$\mathrm{EVT}=$ endovascular thrombectomy; NA=Not applicable.

*Includes lesions that are sub-occlusive, distal, or poor access.

treatment included changes in occlusion characteristics posttransfer $(33 \%)$, mild stroke severity $(15 \%)$, non-suitable or inaccessible occlusion sites $(11 \%)$, comorbidities precluding EVT $(6 \%)$, and lack of consent $(1 \%)$.

\section{Time from Onset to EVT Center Arrival and Probability of Treatment}

There was no association between time from onset to arrival to EVT center and the RR of receiving EVT treatment in the full cohort, even after adjusting for baseline characteristics (Figure 1). However, among the patients who were evaluated at the EVT center within 6 hours of last seen normal time, the probability of treatment with EVT decreased by $3 \%$ with every 10 -minute delay (unadjusted RR 0.97, 95\% CI [0.96, 0.99] and adjusted RR 0.97, 95\%CI [0.95, 0.99], Table 3). No statistically significant association was found in patients that arrived at the EVT center between 6 and 24 hours from last seen normal time or in any other subgroup analyses, including analysis by occlusion site (Supplemental Table 1).

\section{Discussion}

We found that $41 \%$ of patients with acute ischemic stroke and LVO within 24 hours of last seen normal time underwent EVT after evaluation at a comprehensive stroke center. While the clinical characteristics and outcomes in patients undergoing EVT have been previously extensively studied, ${ }^{6,7,11}$ less is known about the number and proportion of patients with LVO who do not receive EVT treatment, as they are not captured in administrative data or clinical registries. ${ }^{6,12}$ Our study examined the specific reasons for non-treatment in these patients and focused on the effect of time on patients' eligibility for EVT. The inclusion of the non-treated patients adds incremental data in this field. We were able to quantify the decrease in EVT probability with increasing time from last seen normal. We showed that the probability of receiving EVT decreased by 


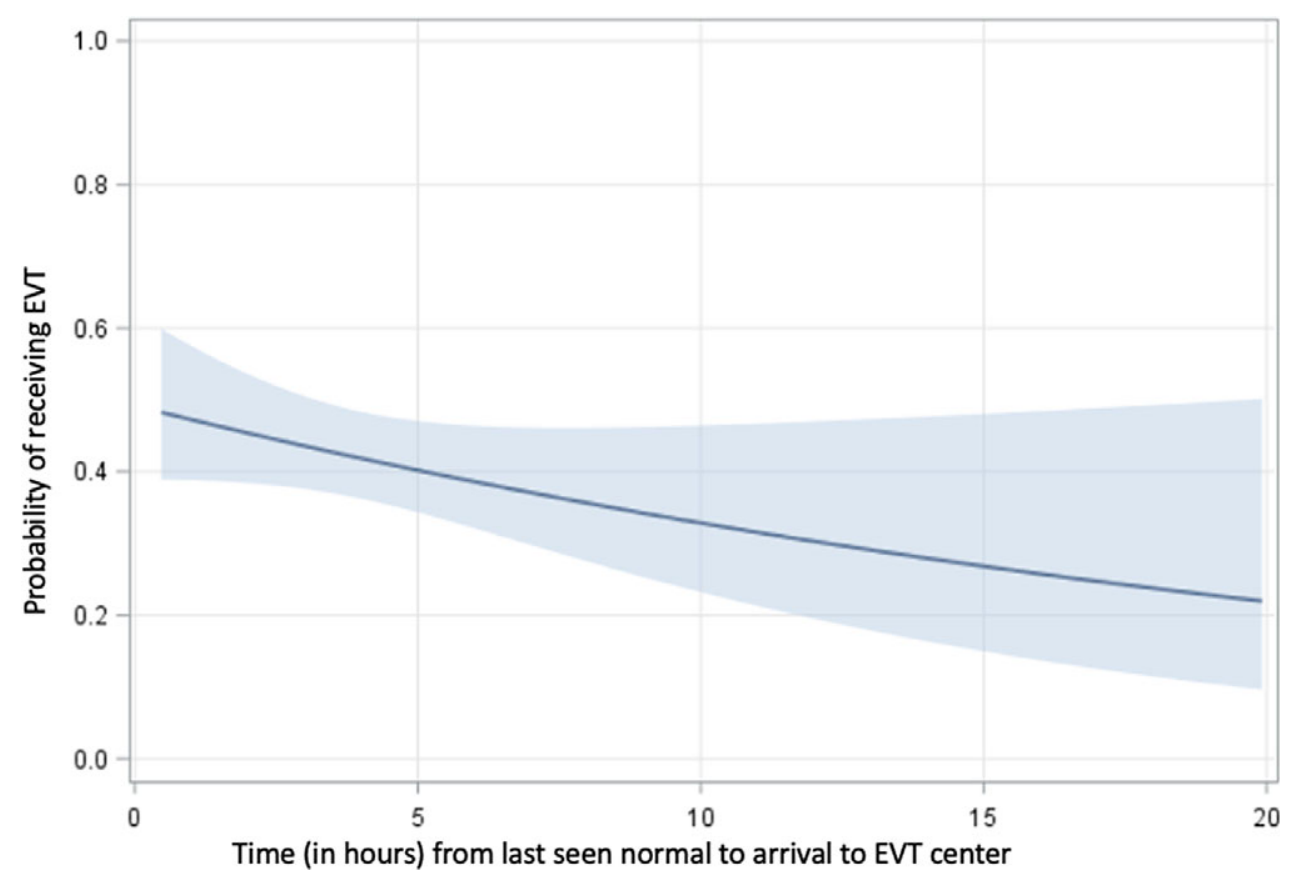

Figure 1: Association between time elapsed between last seen normal and arrival to stroke center and the probability of receiving endovascular thrombectomy (EVT). The solid line represents the fitted model and the shaded area represents the $95 \%$ confidence bands.

Table 3: The association between time from last seen normal to arrival to EVT center in 10-minute increments and risk of receiving EVT $(n=256)$

\begin{tabular}{l|c|c|c}
\hline & $\mathbf{n} / \mathbf{N}$ & Risk ratio & $\begin{array}{c}\text { Adjusted risk } \\
\text { ratio }\end{array}$ \\
\hline Full cohort & $106 / 256$ & $0.99(0.99-1.00)$ & $0.99(0.98-1.00)$ \\
\hline $\begin{array}{l}\text { Time from last seen } \\
\text { normal }\end{array}$ & & & \\
\hline$\leq 6$ hours & $87 / 210$ & $0.98(0.96-0.99)$ & $0.97(0.95-0.99)$ \\
\hline$>6$ hours & $19 / 47$ & $0.99(0.97-1.01)$ & $1.00(0.98-1.04)^{*}$ \\
\hline
\end{tabular}

EVT=endovascular thrombectomy.

*Log-binomial models did not converge due to low sample size; therefore, this estimate of association was derived using HPGENSELECT function in SAS, using logarithmic link and binary distribution to mimic log-binomial models.

$3 \%$ with every 10-minute delay in arrival to the EVT center in patients presenting within 6 hours from symptom onset. Ten minutes is an actionable time interval to target quality improvement strategies aimed at optimizing processes of care to reduce time delays and improve EVT access.

Our findings are consistent with a prior publication conducted between 2006 and 2010 which focused on patients after interhospital transfer, reporting a 3\% decrease in EVT eligibility per minute of transfer time. ${ }^{13}$ We did not find an association between time and probability of receiving EVT in patients presenting in the 6-24-hour time window, but there were few patients in this subgroup, likely because guidelines on extended-window EVT were published toward the end of our study period. ${ }^{4}$ Furthermore, late-presenters may be enriched with patients who exhibit slow infarct progression and thus behave differently. ${ }^{14}$

We found that $66 \%$ of patients transferred for EVT consideration with confirmed LVO ultimately did not receive this treatment. Of these patients, $25 \%$ had infarct progression, but another $30 \%$ were not treated because there was vessel recanalization or distal thrombus migration upon repeat imaging. This is comparable with a recent study from France that found 73 out of $278(26 \%)$ acute stroke patients with LVO had clinical improvement or arterial recanalization after transfer and thus did not receive endovascular therapy. ${ }^{15}$ However, their study period predated the landmark trials demonstrating EVT benefits up to 24 hours and they only included patients presenting within 4.5 hours of stroke onset. They found that patients who were not treated with EVT due to clinical improvement or recanalization had better outcomes at 3 months comparing to those not treated due to other reasons ( $74 \%$ vs. $17 \%$ mRS 0-2). This suggests EVT avoidance due to vessel recanalization or thrombus migration may be a desired outcome for some patients. Dedicated largescale studies are necessary to verify this finding.

The presence of established infarct was the second most frequently cited reason for non-treatment in our study, regardless of whether they presented directly or after inter-hospital transfer. Prior studies found that one in three patients became ineligible for EVT following transfer due to unfavorable ASPECTS decay. ${ }^{16,17}$ Infarct progression depends both on time from onset to assessment as well as individual factors such as collateral status. ${ }^{18}$ From a health system point of view, these transfers should not be considered "futile" as the patients were eligible for EVT at the time of transfer. ${ }^{19}$ Therefore, our findings suggest that many patients with LVO were appropriately transferred for EVT assessment and evidenced-based guidelines were followed in determining eligibility for treatment. However, we also found 
potential opportunities for improving EVT access, for instance, in the patients deemed ineligible for treatment due to infarct progression. Further studies on the effect of collateral status as well as other clinical or radiologic factors to predict infarct growth rate are needed to inform transfer decisions and individualize care.

There are several limitations to our study that warrant discussion. First, this was a single-center study where treatment decisions may be influenced by local practice, patient population, and geographic challenges and therefore our findings require further validation through larger-scale studies. Second, we did not have access to outcome data because many patients were transferred back to the referring hospitals after an initial short observation period. In addition, we did not have access to the time metrics during transfer, which could be helpful to shed light on the processes of care. Finally, we found that $41 \%$ of the patients received EVT, which was lower than prior reports showing a treatment rate of 55\%-65\%. . $^{5}, 15$ Given the later part of our study period overlapped with guideline changes following landmark trials showing the benefits of EVT up to 24 hours, our findings may be a reflection of lower thresholds for accepting patients with LVO in transfer. ${ }^{20}$

\section{Conclusions}

Our study demonstrated that a substantial number of acute stroke patients with LVO ultimately do not receive EVT and further characterized the reasons for non-treatment. The probability of receiving EVT decreased with increasing time to arrival a comprehensive stroke center. Our findings highlight the need to capture data on patients with acute stroke and LVOs who are treated with EVT as well as those who are not.

\section{CONFLict OF INTEREST}

MMG, JZW, JL, SDR, MVV, EL and LC report no conflicts of interest. RHS reports other from Heart and Stroke Foundation of Canada during the conduct of the study. CDK reports personal fees from Alexion, personal fees from Takeda, personal fees from Akcea and personal fees from Sanofi Genzyme outside the submitted work. AYXY reports grants from Heart and Stroke Foundation of Canada, grants from Canadian Institutes of Health Research and grants from Academic Health Sciences Centres of Ontario outside the submitted work.

\section{Statement of Authorship}

Co-authors contributed to the study design (MMG, JZW, CDK, AYXY), data collection (MMG, JZW, JL, SDR), data analysis (MVV, AYXY), and manuscript drafting (MMG, JZW, AYXY). All authors contributed to data interpretation, manuscript revision, and provided final approval.

\section{SUPPLEMENTARY MATERIAL}

To view supplementary material for this article, please visit https://doi.org/10.1017/cjn.2020.95.

\section{REFERENCES}

1. Nogueira RG, Jadhav AP, Haussen DC, et al. Thrombectomy 6 to 24 hours after stroke with a mismatch between deficit and infarct. N Engl J Med. 2018;378:11-21.

2. Albers GW, Marks MP, Kemp S, et al. Thrombectomy for stroke at 6 to 16 hours with selection by perfusion imaging. N Engl J Med. 2018;378:708-18.

3. Saver JL, Goyal M, van der Lugt A, et al. Time to treatment with endovascular thrombectomy and outcomes from ischemic stroke: a meta-analysis. JAMA. 2016;316:1279-88

4. Powers WJ, Rabinstein AA, Ackerson T, et al. Guidelines for the early management of patients with acute ischemic stroke: a guideline for healthcare professionals from the american heart association/american stroke association. Stroke. 2018;49: e46-e110.

5. Fuentes B, Alonso de Lecinana M, Ximenez-Carrillo A, et al. Futile interhospital transfer for endovascular treatment in acute ischemic stroke: the Madrid stroke network experience. Stroke. 2015; 46:2156-61.

6. Mulder M, Jansen IGH, Goldhoorn RB, et al. Time to endovascular treatment and outcome in acute ischemic stroke: MR CLEAN registry results. Circulation. 2018;138:232-240.

7. Jahan R, Saver JL, Schwamm LH, et al. Association between time to treatment with endovascular reperfusion therapy and outcomes in patients with acute ischemic stroke treated in clinical practice. JAMA. 2019;322:252-63.

8. Lakomkin N, Dhamoon M, Carroll K, et al. Prevalence of large vessel occlusion in patients presenting with acute ischemic strokes: a 10-year systemic review of the literature. J Neurointervent Surg. 2019;11:241-45.

9. Goyal M, Demchuk AM, Menon BK, et al. Radomized assessment of rapid endovascular treatment of ischemic stroke. N Engl J Med. 2015;372:1019-30.

10. Berkhemer OA, Fransen PSS, Beumer D, et al. A randomized trial of intraarterial treatment for acute ischemic stroke. N Engl J Med. 2015;372:11-20.

11. Jansen IGH, Mulder M, Goodhoorn RB, et al. Endovascular treatment for acute ischemic stroke in routine clinical practice: prospective, observational cohort study (MR CLEAN Registry). BMJ. 2018;360:k949.

12. Stein LK, Tuhrim S, Fifi J, et al. Interhospital transfers for endovascular therapy for acute ischemic stroke: national representative data. Stroke. 2019;50:1789-98.

13. Prabhakaran S, Ward E, John S, et al. Transfer delay is a major factor limiting the use of intra-arterial treatment in acute ischemic stroke. Stroke. 2011;42:1626-1630.

14. Sarraj A, Mlynash M, Savitz SI, et al. Outcomes of thrombectomy in transferred patients with ischemic stroke in the late window: a subanalysis from the DEFUSE 3 trial. JAMA Neurol. 2019; 76:682-89.

15. Sablot D, Dumitrana A, Leibinger F, et al. Futile inter-hospital transfer for mechanical thrombectomy in a semi-rural context: analysis of a 6-year prospective registry. J Neurointerv Surg. 2019;11:539-44.

16. Mokin M, Gupta R, Guerrero WR, et al. ASPECTS decay during inter-facility transfer in patients with large vessel occlusion strokes. J Neurointerv Surg. 2017;9:442-44.

17. Nikoubashman O, Pauli F, Schurmann K, et al. Transfer of stroke patients impairs eligibility for endovascular stroke treatment. J Neuroradiol. 2018;45:49-53.

18. Boulouis G, Laurer A, Siddiqui AK, et al. Clinical imaging factors associated with infarct progression in patients with ischemic stroke during transfer for mechanical thrombectomy. JAMA Neurol. 2017;73:1361-67.

19. Goyal M, Menon BK, Wilson AT, et al. Primary to comprehensive stroke center transfers: appropriateness, not futility. Int J Stroke. 2018;13:550-53.

20. Shah S, Xian Y, Sheng S, et al. Use, temporal trends, and outcomes of endovascular therapy after interhospital transfer in the United States. Circulation. 2019;139:1568-77. 